\title{
Curriculum Weaving: Developing Creative Curricular Opportunities for Pre-Service Teachers and Elementary Students through Project-Based Learning
}

\author{
Alison Lynn DuBois ${ }^{1, *} \&$ Tina Marie Keller $^{2}$ \\ ${ }^{1}$ School of Education, Westminster College, United States \\ ${ }^{2}$ School of Education, Messiah College, United States \\ *Correspondence: School of Education, Westminster College, United States. E-mail: duboisal@westminster.edu
}

Received: August 3, 2016

Accepted: September 10, 2016 Online Published: September 26, 2016

doi:10.5430/jct.v5n2p37

URL: http://dx.doi.org/10.5430/jct.v5n2p37

\begin{abstract}
Curriculum Weaving uses multi-layered goal planning designed to activate the students' prior knowledge, connect the student to student competencies and encourage them to engage in professionally-based, project management activities that will cultivate effective professional in the field classroom teacher. The focus of weaving these elements together through a project based event fosters a shift to a more holistic and contextualized perspective of the learner. In our model of Curriculum Weaving, we see this process as one that describes the uniting of daily theoretical requirements, student lived experiences, and intangible skill sets into a larger perspective of learning as represented by holistic thinking. The following article describes the Curriculum Weaving Model as it was applied to a children's book author visit.
\end{abstract}

Keywords: project-based learning; intangible skills; contextualized learning; ESL; children's literature

\section{Introduction}

Watching a master weaver skillfully move a shuttle of yarn back and forth between the rows of a taut threaded loom can compel one to realize the importance of perspective. Initially, the novice observer's focus is on each newly added line of yarn. Observing the weaver's rhythmic tempo, the eye automatically goes to the moving addition-noticing how it is pulled tightly into line with the previous row. After a few minutes, however, the observer's focus begins to change. As the colorful pieces of yarn form a design, the pattern becomes more intricately detailed; more vibrant. There is a shift in attention from each line of yarn, to the larger pattern emerging in the fabric. As the tapestry takes shape forming the final project, the weaver's point of view and focus has also changed. One must shift the eyes to holistically view the entirety of the emerging design. While the casual observer may be unable to see how each line of yarn contributes to the whole, the master weaver planned the pattern from the start. While each thread is important, it was the pattern, not the isolated threads which guided the work. The contrast between the observer and the master weaver was a difference in perspective.

The same can hold true in curriculum design in higher education. One can become so focused upon the theoretical, daily objectives of instruction, the pressures to fulfill standards, and the passing of standardized, state certification tests-that the larger, layered, multicolored, elements of the curriculum go unfulfilled. The big picture is obscured by the immediate, short term (often academic) objectives. This focus, while important, diminishes the opportunities for college students to develop intangible skills needed to successfully teach in the classroom. Loughran (2013) suggests "teacher education must purposefully embed learning about the complexity of teaching within experiences of its problematic nature...this should be reflected in the manner in which learning about teaching is constructed” (p.1178). Curriculum weaving can be embedded throughout a teacher education program. We have applied this concept to various aspects of undergraduate research, migrant tutoring, and course development. This article, however, will further elucidate our concept of Curriculum Weaving and how it was applied to a particular project-based learning activity in a teacher education program. 


\section{Curriculum Weaving: An Artful Change in Perspective}

The tapestry or weaving metaphor has been used in myriad ways-including the sciences, student health, end of life curricula, and education (Campbell, 2007; Doorenboos, A., Briller, S., \& Chapelski, E., 2003; Olson, T. \& Riley, J, 2009; Simon, 2013). Based on Cazden's (2006) idea of weaving as defined as those moments in the classrooms when, "explicit connections are made-by teacher or students-across one or another dimension of knowledge. Usually, weavings connect something that is already familiar with new curriculum content" (p.1). In our model of Curriculum Weaving, we see this process as one that describes the uniting of daily theoretical requirements, student lived experiences, and intangible skill sets into a larger perspective of learning as represented by holistic thinking. (See Figure One). Curriculum Weaving uses multi-layered, well-developed goals which address a continuum of college level objectives. These goals are designed to activate the students' prior knowledge, connect the student to student competencies and encourage them to engage in professionally-based, project management activities that will cultivate effective professional in the field classroom teacher. The weaving together of these elements through a project based event fosters a shift to a more holistic and contextualized perspective of a learner experiencing the learning process.

\section{Threads of the Curriculum Weaving Model (refer to figure 1)}

This section will discuss the theoretical underpinnings and application of the model within the framework of a teacher education program. Curriculum Weaving is a project-based event that seeks to weave together three elements; theoretical requirements, lived experiences, and intangible skills sets. Often these three elements are difficult to integrate within the four walls of a traditional higher education classroom. We believe that the purposeful weaving together of these elements not only gives meaning to each aspect, but it provides the opportunity to acknowledge, foster, and practice these skills in context.

Theoretical requirements. Pre-Service Teacher candidate competencies established by the State's department of education provide teacher educators with a framework of what learning objectives should be incorporated throughout a student's four-year sequence. These are curricular requirements (i.e. Foundations in Education or Student teaching) that must be taught or supervised. Danielson's Framework also fits into the Curriculum Weaving Model in this area. Students acquire and cultivate a skill set that includes Danielson's four domains. Project-based learning that incorporates PST learner objectives was developed to address an oft overlooked area of teacher development. Darling-Hammond (2000) suggests that

accredited programs must now demonstrate that they prepare teachers with deep knowledge of the content areas they teach and with solid understanding of learning, teaching, curriculum, assessment, and the uses of technology, among other things (p. 6).

Lived Experiences. The foundation of this area is rooted in constructivist practices which are inherently collaborative and dynamic-encouraging students to be active participants in their learning. The development of metacognitive skills is a critical element in the learning process. Strong metacognitive skills affect how much and how deeply a student learns. These competencies can include the ability to identify skills needed to organize and acquire information, identifying the most efficient way to process and present information, to evaluate strategies used throughout the process, and adapt the strategies for generalization into various events or environments (Hunt, N. \& Marshall, K. 2012). Project based learning is a tool that can be employed to foster the development of these metacognitive skills (Hicks. R., 1996). According to Vygotsky (1978), students begin a project within their actual developmental level, but through problem solving under adult guidance and/or collaboration with peers, they have the ability to mature to their full potential. Project based learning also lends itself to the development of mentoring-type relationships between Teacher Educators, Practicing Teachers, and PST. Learners modify, reinterpret, and integrate new knowledge with information previously acquired (Feiman-Nemser, 2013). This new information is also filtered through the learners' social and cultural contexts (Feiman-Nemser, 2013). Mentors, therefore, become an integral part of the learners' contextual "Loom". While some PST have had lived experiences encompassing academic, personal, and cultural areas affording them opportunities to strengthen and reflect upon these attributes, many have not had such exposure. As a result, educators in higher education must create events to cultivate these skills.

Intangible skill set. The first skill, Project management includes organization, planning, execution, and analysis. Leadership takes into account learner motivation and initiative. Adaptability forces the learners to be flexible in their decision-making and problem-solving processes. Lastly, Professionalism was included which incorporates effective listening, communication skills, and development of a professional identity. Feiman-Nemser (2013) states, “ learning to think like a teacher requires a critical examination of one's existing beliefs, a transition to pedagogical thinking, and the development of meta-cognitive awareness" (p. 698). We sought to design an event that would enable PST the 
opportunity to develop the professionalism, resiliency, creativity, and curiosity under the guidance of teacher educators and classroom teachers.

\section{Curriculum Weaving in Teacher Education}

Curriculum Weaving in teacher education creates learning experiences that are embedded throughout the four-year undergraduate experience cultivating the students' acquisition of theoretical concepts in education. In addition, transferable, often intangible skill sets are developed in the classroom. This model examines these experiences on a continuum that allows participants to move recursively from one area to another. When a project (or event) is chosen, the creators intentionally plan to ensure that meaningful connections are being made. This process is also highly dependent on the collaboration of key stakeholders-which can range from higher education practitioners to students to elementary education administration and staff. For example, Pre-Service Teachers (PST) are encouraged to reflectively evaluate how their lived experiences influence the professional they will become.

Classroom-based learning activities enable PST to work on a number of skills necessary for the school environment. Some skills, such as planning, organization, execution, are naturally embedded into the process and are a natural fit for the mandated PST learning objectives. Other intangible skills, such as leadership development, effective communication, reflection, flexible thinking, and professionalism are also highlighted. Curriculum weaving events can therefore be customized throughout the course of a degree program to address specific goals and needs of preservice teachers. We sought to create a connection between the development of these intangible skill sets and candidate competencies found in most pre-service teacher programs. The next section will discuss the construction of the Model and how it was applied to a single event.

\section{Specific Goals for a Project-based Learning Event}

Each year, a children's book author visit is organized in collaboration with area school districts. Over the course of multiple years, the teacher educator faculty observed PST who demonstrated weaknesses during student teaching which required the application of "intangible" skills-typically not included in teacher education curricula. We sought to identify these "intangible" skills and focused on four that enabled our learners to participate in authentic, experiential, reflective activities.

There are three key goals that were the main focus in planning our Curriculum Weaving event. The initial piece begins with teacher educators who have an interest in project-based learning activities. These activities provide students with experiential, active learning events. Fink's (2003) inclusion of social interactions and learner motivation create a bridge between state-mandated learner objectives and competencies and the inevitable, intangible learning that takes place throughout a program. The planning of a curriculum weaving event would certainly take into account the required pre-service teacher objectives that must be covered by the higher education curriculum including our State's Board of Education, Interstate New Teacher Assessment and Support Consortium (INTASC), and the Council for Accreditation of Teacher Preparation (CAEP). Upon reviewing these candidate competencies, teacher educators can then match these to specific goals developed to execute the activity or event. With any project-based learning activity there are a set of skills that all learners must demonstrate such as organization, planning, problem-solving, and analysis/reflection (Clark, R. 2008). These objectives are embedded into each project naturally.

Our second goal was to incorporate experiences into each event that also develops intangible skills of the participants, such as leadership, effective communication, flexible thinking, and professionalism. Students were included in the planning stages to create learner motivation. This also enables the students to move up and down Bloom's Taxonomy-increasing their cognition levels related to the material. As a result, the students engaged in authentic learning experiences that were active and reflective. The educational environment was more conducive to what Fink (2003) refers to as Significant Learning, thus creating reflective students who are moving beyond the prescribed curriculum and expected application of pre-determined Pre-service Teacher skills.

The last goal to this event examined the role of the elementary school administration/staff/students. Both teacher educators and college students work with elementary school faculty to create inter-curricular connections that include creative lesson planning that addresses the Common Core and State Learning Standards.

\section{Planning Phase}

We applied the aforementioned goals to the four domains of Danielson's Framework (2008) during the planning phase. This section will outline how we addressed our goals in the planning stages. A parallel process unfolded that involved 
Teacher Educators and PST. Planning and Preparation, Classroom Environment, Instruction, and Professional Responsibility (Danielson, 2008) were considered throughout the initial design of the event. This process included identification of State Teacher Candidacy Objectives and curricular goals. In addition, pre-service teacher candidates participated in the second phase which included the organization, planning and execution of the event in collaboration with the campus and elementary school communities. In Pennsylvania, Danielson's framework (2008) serves as the theoretical foundation for our teaching goals. The Framework is currently used in a variety of ways ranging from professional development to teacher evaluation (Danielson, 2008). The added benefit of using Danielson's Framework from a Teacher Educator perspective is that it also provided another assessment tool to be used for our pre-service teacher candidates.

Danielson's domains. In the first phase of planning, we targeted one PST goal in each of the Danielson's four domains. They were as follows: 1 . Sets long-term curricular goals and demonstrates logical order in planning, 2. Encourages Critical Thinking, 3. Engages learners, and 4. Cultivates professional relationships with faculty, parents, and community.

Sets Long-term curricular goals. Students were involved in all facets of planning including author selection, organization of the schedule on the day of the visit, K-6 student and teacher preparation in anticipation of the visit, and reflection of the event.

Encourages Critical Thinking. Students also had to work as a collective body to execute fundraisers to contribute financially to the visit. They had to develop a budget and decide how the money raised would be spent. Depending on the school district, this might include paying for the author's travel expenses or buying books for the children.

Engages Learners. Students had to demonstrate working knowledge of the States K-6 learning objectives and created lesson plans that were implemented by the K-6 teaching staff. The students also conducted a writing contest for the K-6 students. Planning included book selection for each grade level that was developmentally appropriate and engaging, developing writing prompts, and a rubric to assess student writing.

\section{Cultivates professional relationships with faculty, parents, and community}

Students worked with college faculty and other campus organizations in the budget planning and organization of the event. They collaborated with K-6 administration, teaching staff, and parent/teacher organization prior to and during the visit. Lastly, students developed the marketing tools (i.e. posters/flyers) and contacted local media outlets to promote the event within the community.

\section{Curriculum Weaving Event: An Author Visits}

As mentioned earlier, the Curriculum Weaving event highlighted in this article was designed around a visit from a nationally awarded children's book author. This event enabled the participants to move beyond both the physical and conceptual constraints of our respective classrooms, thereby envisioning a curriculum-rich, relevant opportunity for myriad levels of learning. This example seeks to describe how two education professors artfully integrated the three threads of teacher preparation into a curriculum weaving event. PST are then exposed to the author's work and provided with a number of "real-life" activities enabling them to engage in meaningful work that targets the intangible and tangible skills required in effective teaching.

\section{Layers of Pre-service Teacher Involvement (In the Author visit)}

Teacher Educators are often engaged in multiple levels of course design. Adhering to state driven standards and teacher competencies are often at the forefront in the planning process. Course objectives and learner goals should move beyond content mastery in an effort to matriculate life-long learners (Fink, 2003). Providing students with opportunities to move beyond theory and enable them to develop problem-solving skills, sequence and coordinate complex tasks, and improve their communication skills are an imperative in today's classroom.

\section{Weaving in Teacher Education Coursework}

Undergraduate first and second year students enrolled in the general education classes were also involved in this Curriculum Weaving event. The principles of integrated curriculum were applied thus enabling students to make connections across a number of disciplines. Several standards in the coursework include adapting materials for ELLs and incorporating literacy into the content area. More often than not, PST complete lesson plans in isolation-devoid of actual students or opportunities to teach. This project provided them with a timely, real world context. In this curriculum weaving event, students divided into small groups, each choosing a picture book written by the author, and began to develop classroom uses for the book. Students were guided to write summaries of the book, create classroom activities utilizing the text and offer extension activities which linked the text to grade level content. Students also 
created reproducible pdf documents that classroom teachers from our school district partners could immediately use in preparing their students for the author's visit. Once the work was revised, it was compiled into a one hundred page booklet that was distributed to both PST, as well as, the classroom teachers at the author visit site. The timing of the booklet distribution was approximately two months prior to the author's visit, thus giving classroom teachers the opportunity to examine ten picture books before the author's visit, and have useable classroom activities at their fingertips.

\section{Reflection Phase: The Tapestry of Learning}

One student commented that this task prepared them for their future roles as teachers as : “... a good chance to see what we, as Pre-Service Teachers, have to look forward to creating one day.” Another student realized that this project was a link not only between her own learning but to support real students in classrooms. She commented, "...making the booklet was a great opportunity to connect classroom techniques to well-known children's books. The booklet will not only help students in my class in their future classroom, but will also help local students and teachers."

The belief that this project was more than a teacher education activity, but a resource that classroom teachers in a neighboring school district was motivational as it allowed students the opportunity to weave these coursework standards into an actual, usable product that had an impact on classroom instruction. This integration of coursework for first and second year education majors allowed PST, in their initial coursework, to become actively involved into the culture and community of teachers in the classroom.

\section{Multilayered Cross Curricular Opportunities for K-6 Students}

Pre-Service Teachers, College Faculty, School Administration and K-6 Classroom Teachers collaborated to create meaningful learning experiences for the K-6 students. This included incorporating the author's work into the curricular instruction, decorating the school for the day of the visit, and participation in activities across physical education and the arts. In physical education, for example, students in each grade learned a different Latin dance that coordinated with one of the author's books. Each grade level then performed the dances for the author on the day of the visit. The Parent/Teacher Organization was also involved throughout the process and provided the author's books for each classroom library. One of the teachers involved in the event stated, "We were very fortunate to have this experience and I hope it inspires some students to become writers and illustrators”.

\section{Conclusion}

Freire (1970) asserts that education should be liberating, not mechanistic or alienating. As illustrated in this article, teachers and students worked together, making meaningful connections, thus building knowledge based upon students' lived experiences and their previous academic learning.

According to Murray (2013), "teacher education programs are remarkably the same in their four part format across the country-(1) general/liberal arts courses, (2) subject matter courses, (3) pedagogical or methods courses, (4) clinical experience courses (p. 1236)”. A disconnect arises when curricular content doesn't address the intangible skill set needed to be effective, reflective practitioners.

As a result of this children's author event, the curriculum for both the elementary students and PST was enhanced and made stronger by the weaving together of multiple layers of curricular goals. This also enabled Teacher Educators a different perspective with which to informally assess PST' competencies. For PST, it brought to life the education department's mission statement as a living, breathing aspect of how we holistically envision teacher education. PST demonstrated confidence and a belief in competence as a result of participation in this event. It gave PST the opportunity to be self-reflective practitioners in determining if their skill sets matched those required of the teaching profession. In the job market, this cohort of PST were participants in unique leadership opportunities-setting them apart from other teaching candidates. Most importantly, nurturing more reflective practitioners has a direct impact on the children that they will eventually teach. Throughout the Curriculum Weaving event, PST are encouraged to become more self-aware and confident, intentional and creative in their planning, and implement more effective assessment measures. Future research into the efficacy of the model should be conducted.

In addition, this way of viewing and articulating an event allowed for teacher educators to untangle the elements of a successful activity-seeking to more purposefully include these elements again in future projects. This model for curriculum planning allows teacher educators to examine and reflect upon their integration of the three elements, seeking to understand how certain threads could be strengthened, or elaborated upon. It allows for a common language or metaphor of curriculum design. Thus fostering interdepartmental conversation and cross pollination of ideas as well as collaboration for future curriculum weaving events. 


\section{References}

Campbell, A. (2007). Weaving women into the science curriculum. Science Scope, 31(2), 54-8.

Cazden, C. (2006). Connected learning: “Weaving” in classroom lessons. In Pedagogy in Practice 2006 Conference. University of Newcastle. Retrieved from http://www.newcastle.edu.au/Resources/Schools/Education/Pedagogy/2006/PiP-2006-keynote.pdf

Danielson, C. (2008). The Handbook for Enhancing Professional Practice: Using the framework for teaching in your school. Association for Supervision and Curriculum Development. Alexandria, VA.

Darling-Hammond, L. (2000). Solving the dilemmas of teacher supply, demand, and standards: How we can ensure a competent, caring, and qualified teacher for every child. New York, NY: National Commission on Teaching and America's Future.

Doorenbos, A., Briller, S., \& Chapleski, E. (2003). Weaving cultural context into an interdisciplinary end-of-life curriculum. Educational Gerontology, 29, 405-416. http://dx.doi.org/10.1080/713844358

Feiman-Nemser, S. (2013). How do teachers learn to teach. In Cochran-Smith, M., Feiman-Nemser, S., McIntyre, D. J., \& Association of Teacher Educators, Handbook of research on teacher education: Enduring questions in changing contexts. New York: Routledge.

Fink, L. D. (2003). Creating meaningful learning experiences. Jossey-Bass: San Francisco, CA.

Hicks, R. (1996). Experiential learning in a post graduate project management programme. Education + Training, 38(3), 28-38. http://dx.doi.org/10.1108/00400919610117399

Hunt, N., \& Marshall, K. (2012). Exceptional children and youth (5 ${ }^{\text {th }}$ Ed.). Cengage Learning: Belmont, CA.

Loughran, J. (2008). Toward a better understanding of teaching and learning about teaching. In Cochran-Smith, M., Feiman-Nemser, S., McIntyre, D. J., \& Association of Teacher Educators, Handbook of research on teacher education: Enduring questions in changing contexts. New York: Routledge.

Murray, F. B. (2013). The role of teacher education courses in teaching by second nature. In Cochran-Smith, M., Feiman-Nemser, S., McIntyre, D. J., \& Association of Teacher Educators, Handbook of research on teacher education: Enduring questions in changing contexts. New York: Routledge.

Olson, T., \& Riley, J. (2009). Weaving the campus safety net by integrating student health issue into the curriculum. About Campus. May-June. http://dx.doi.org/10.1002/abc.286

Simon, S. E. (2013). The weaving of a tapestry: A metaphor for teacher education curriculum development. Australian Journal of Teacher Education, 38(8), 73-90. http://dx.doi.org/10.14221/ajte.2013v38n8.5

Vygotsky, L.S. (1978). Mind in society. Harvard University Press: Cambridge, MA. 